\title{
Mobile genetic elements of Staphylococcus aureus
}

\author{
Natalia Malachowa $\cdot$ Frank R. DeLeo
}

Received: 25 February 2010/Revised: 6 April 2010/ Accepted: 26 April 2010/Published online: 29 July 2010

(C) The Author(s) 2010. This article is published with open access at Springerlink.com

\begin{abstract}
Bacteria such as Staphylococcus aureus are successful as commensal organisms or pathogens in part because they adapt rapidly to selective pressures imparted by the human host. Mobile genetic elements (MGEs) play a central role in this adaptation process and are a means to transfer genetic information (DNA) among and within bacterial species. Importantly, MGEs encode putative virulence factors and molecules that confer resistance to antibiotics, including the gene that confers resistance to beta-lactam antibiotics in methicillin-resistant $S$. aureus (MRSA). Inasmuch as MRSA infections are a significant problem worldwide and continue to emerge in epidemic waves, there has been significant effort to improve diagnostic assays and to develop new antimicrobial agents for treatment of disease. Our understanding of S. aureus MGEs and the molecules they encode has played an important role toward these ends and has provided detailed insight into the evolution of antimicrobial resistance mechanisms and virulence.
\end{abstract}

Keywords Mobile genetic elements ·

Staphylococcus aureus - Virulence - Antibiotic resistance . Horizontal gene transfer

N. Malachowa $\cdot$ F. R. DeLeo $(\bowtie)$

Laboratory of Human Bacterial Pathogenesis,

Rocky Mountain Laboratories, National Institute of Allergy

and Infectious Diseases, National Institutes of Health,

903 South 4th Street, Hamilton, MT 59840, USA

e-mail: fdeleo@niaid.nih.gov

\section{Introduction}

Mobile genetic elements (MGEs) were first described in the maize genome in the late 1940s [1,2] and are an important means for transfer of genetic information among prokaryotes and eukaryotes. MGEs are typically identified as fragments of DNA that encode a variety of virulence and resistance determinants as well as the enzymes that mediate their own transfer and integration into new host DNA [3]. MGEs demonstrate intracellular and intercellular mobility, and those within one particular cell are called a "mobilome" [4]. Transfer of MGEs between cells is known as lateral or horizontal gene transfer (HGT). HGT occurs as prokaryote-to-prokaryote, prokaryote-to-eukaryote, and eukaryote-to-eukaryote transfer of DNA [5, 6] (Fig. 1). MGEs may consist of insertion sequences, transposons, phages, plasmids, pathogenicity islands, and chromosome cassettes. These segments of DNA are largely propagated by vertical gene transfer, which is transmission of genetic information from parent to progeny cell (Fig. 1).

The bacterial genome consists of core and accessory genomes. The core genome contains all genes vital to cell survival, such as genes encoding molecules involved in metabolism, DNA and RNA synthesis, and replication. The accessory gene pool represents the diversity within bacterial species by encoding proteins required for adaptation of bacteria in different ecological niches (resistance, virulence factors, etc.). Accessory genes typically have a different $\mathrm{G}+\mathrm{C}$ content than those in the core genome, often because they are obtained from other species of bacteria $[7,8]$. Bacteria obtain genetic information from other cells or the surrounding environment in three ways: (1) uptake of free DNA from the environment (transformation), (2) bacteriophage transduction, and (3) direct contact between bacterial cells (conjugation). 


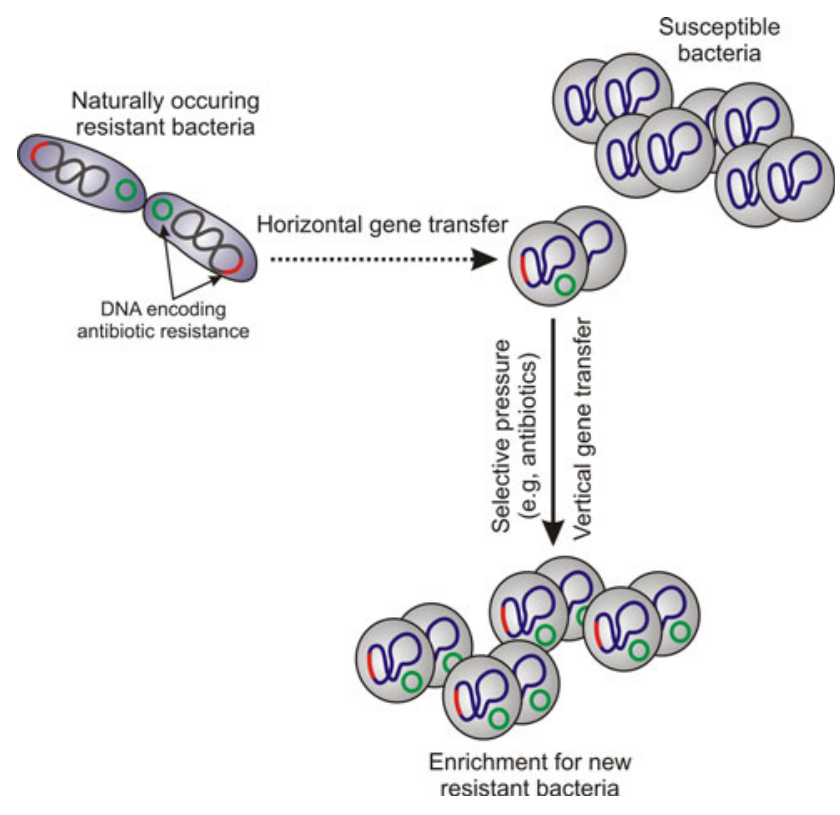

Fig. 1 Horizontal and vertical gene transfer

In prokaryotes, transfer of genetic information between cells and among different species or genera is one of the main forces that generate "step change" or quantum leap evolution [7]. Extrachromosomal DNA elements such as MGEs play a crucial role in the plasticity of the genome, allowing bacteria to adjust readily to new environments. Selective pressure from the environment drives enrichment for specific genes that promote fitness and survival. An example of selective pressure is that imparted by use of antibiotics, which promotes development or acquisition of antibiotic resistance in bacteria. Inasmuch as $S$. aureus is notorious for acquiring resistance to antibiotics, some of which is encoded by MGEs, and also contains many putative virulence molecules on MGEs, it is an ideal model bacterium for the purpose of this review.

\section{S. aureus MGEs}

The genus Staphylococcus consists of Gram-positive bacteria that colonize human or animal skin and mucosal membranes. Although staphylococci are a part of normal human flora and thus commensal microorganisms, they are also opportunistic pathogens and cause a wide range of diseases. Among staphylococci, S. aureus is the most invasive species and an etiological agent of diverse human and animal maladies, including skin infections, abscesses, food poisoning, toxic shock syndrome, septicemia, endocarditis, and pneumonia [9-11]. S. aureus is one of the most prominent causes of nosocomial- and communityacquired bacterial infections worldwide [12]. Although the basis for this cadre of diseases is multifactorial and largely dependent on host susceptibility, heterogeneity of S. aureus strains likely plays a role in this process. Heterogeneity among $S$. aureus strains develops in part as a consequence of its interaction with the mammalian host. Numerous putative and proven virulence factors, genes responsible directly for host adaptation, and toxins, are located on S. aureus MGEs [8, 13-22]. S. aureus contains many types of MGEs, including plasmids, transposons (Tn), insertion sequences (IS), bacteriophages, pathogenicity islands, and staphylococcal cassette chromosomes (Figs. 2 and 3). It is remarkable that most genes encoded by MGEs remain under the control of global regulators located within the core genome.

\section{Plasmid-encoded antibiotic resistance}

Plasmids are auto-replicating DNA molecules. Staphylococci typically carry one or more plasmids per cell and these plasmids have varied gene content. Staphylococcal plasmids can be classified into one of the three following groups: (1) small multicopy plasmids that are cryptic or carry a single resistance determinant; (2) larger (15-30 kb) low copy (4-6/cell) plasmids, which usually carry several resistance determinants; and (3) conjugative multiresistance plasmids [23]. Larger plasmids undergo theta replication

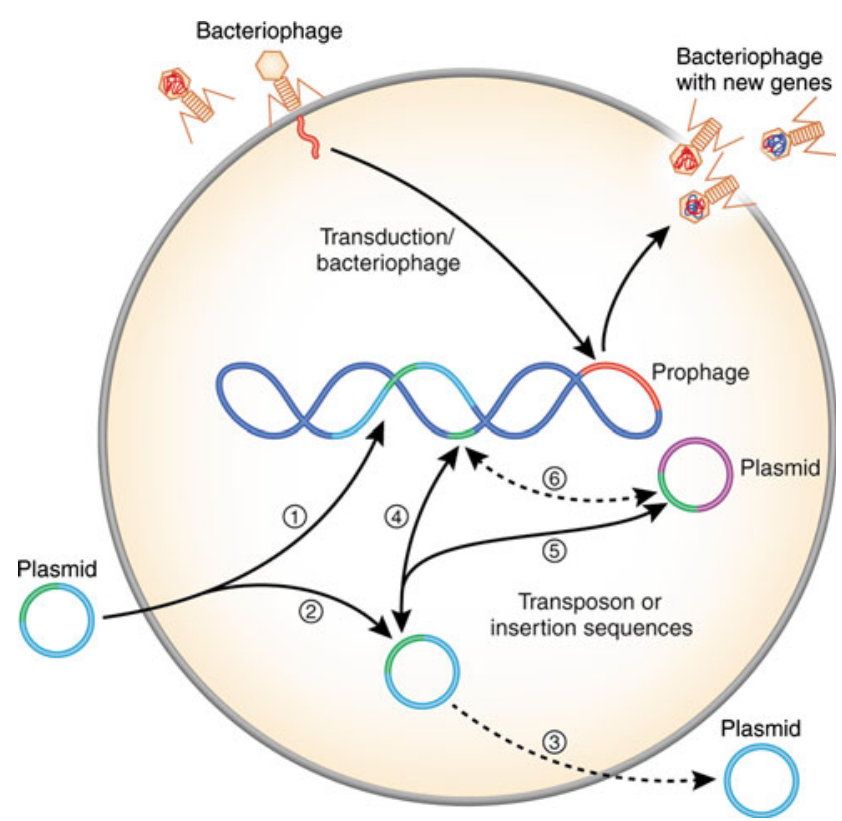

Fig. 2 Acquisition of MGEs by $S$. aureus. 1 Incorporation of plasmids or plasmid elements into genomic DNA. 2 Plasmids can be maintained as free circular DNA. 3 Suicide plasmid. 4 Transfer of a transposon or an insertion sequence between plasmid and genomic DNA. 5 Transfer of a transposon or an insertion sequence between plasmids within the cell. 6 Transfer of a transposon or an insertion sequence from genomic DNA to another plasmid 


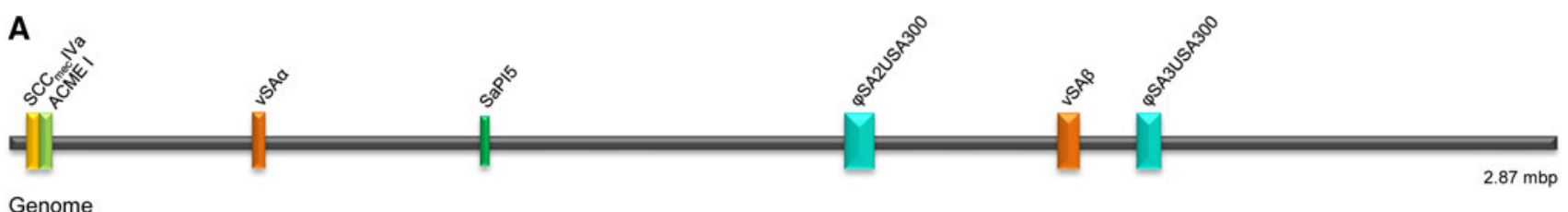

Genome

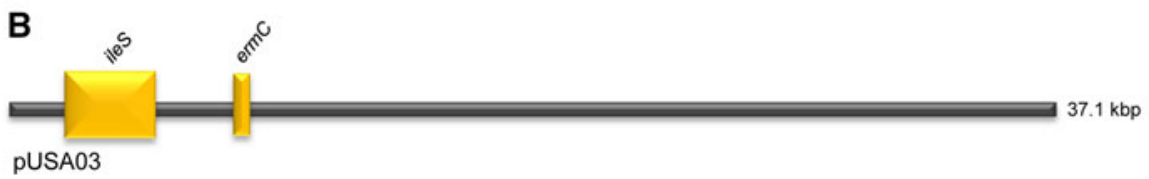

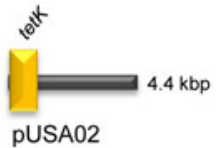

$3.1 \mathrm{kbp}$

pUSA01

Fig. 3 Linear schematic of the USA300 genome (strain FPR3757) and its major MGEs. a Genome. $\mathrm{SCC}_{\mathrm{mec}} \mathrm{IVa}$ encodes methicillin resistance. $v \mathrm{SA} \alpha$ encodes $l p l, s s l$ and $v \mathrm{SA} \beta$ encodes $l u k D E, s p l, b s a$. SaPI5 encodes seq 2 and sek2, $\varphi$ SA2USA300 encodes $l u k S / F-P V$, and

(a DNA replication mechanism that resembles the Greek letter theta), whereas small plasmids usually replicate by the rolling-circle mechanism [24, 25]. As a consequence of the limited ability of $S$. aureus to acquire DNA from the environment (low natural competence) compared to bacteria such as Escherichia coli or Bacillus subtilis, most of the intercellular transfer of staphylococcal plasmids occurs by transduction or conjugation [26]. Upon entering the bacterial host, staphylococcal plasmids remain as free circularized DNA or linearize and integrate into the chromosome (Fig. 2).

Penicillin was the first antibiotic mass produced for use in humans. Although initially highly effective for treatment of $S$. aureus infections, today over $90 \%$ of human S. aureus strains are resistant to this antibiotic [27]. Penicillin resistance is conferred by $\beta$-lactamase, which hydrolyzes the $\beta$-lactam ring of penicillin thereby inactivating the antibiotic, and/or production of a low-affinity penicillin-binding protein (PBP2a) encoded by the mecA gene [12, 27, 28]. In $S$. aureus, $\beta$-lactamase is encoded by the blaZ gene and the closely linked regulatory genes, blaI and blaR [28]. Aside from plasmid encoded $\beta$-lactamase, bla genes may be located on transposons or within chromosomal DNA [27, 29].

More recently, S. aureus acquired vancomycin resistance elements from enterococci, resulting in the emergence of vancomycin-resistant $S$. aureus (VRSA) [30, 31]. Compared with vancomycin-intermediate $S$. aureus (VISA, MIC: $4-8 \mu \mathrm{g} / \mathrm{ml}$ ), in which the mechanism of resistance is incompletely determined [32], high-level vancomycin resistance (that in VRSA) or VanA-mediated resistance is better characterized [30, 33, 34].

Tn1546 encodes the vancomycin resistance gene cluster within a conjugative plasmid. This MGE was most likely transferred to methicillin-resistant $S$. aureus (MRSA) from vancomycin-resistant enterococci (VRE) during co-infection $[25,30,31,35]$. There are two predicted fates of the enterococcal plasmid upon entering staphylococci. On one hand, the enterococcal plasmid could simply be maintained, as occurred with strains VRSA-3, 5, and $6[31,36]$. Alternatively, $\operatorname{Tn} 1546$ could be incorporated into a staphylococcal plasmid (VRSA-1, 7, 8, 9, and 10; plasmid pLW1043) in which case the original enterococcal plasmid functions as a suicide vector $[31,36]$. Transposon $\operatorname{Tn} 1546$ encodes the vanA operon, which consists of vanA, vanH, vanX, vanS, vanR, van $Y$ and $\operatorname{vanZ}[30,38]$. It is interesting that, for the second VRSA isolate reported in the US (VRSA-2), the van operon is located within a truncated Tn1546 on a 120 -kbp plasmid, which is an unusually large plasmid for $S$. aureus [37]. vanA and $v a n H$ are responsible for synthesis of a D-Ala-D-Lac precursor that has much lower affinity to glycopeptide antibiotics than the original D-Ala-D-Ala. vanX encodes a dipeptidase that plays a role in the elimination of wild-type D-Ala-D-Ala targets by hydrolysis [39]. Expression of vancomycin resistance genes occurs only in the presence of vancomycin, a process mediated by a two-component signal transduction system encoded by vanS and vanR. vanY and vanZ encode an accessory protein that could play a role in teicoplanin resistance $[34,40]$. 
In addition to genes encoding antibiotic resistance and molecules involved in metabolism, staphylococcal plasmids encode resistance to a variety of organic and inorganic ions, such as cadmium, mercury, arsenate, etc., which are highly toxic for living cells (Table 1) [41]. Staphylococcal plasmids may also encode toxin genes. For example, a large 37.5-kb S. aureus plasmid, pRW001, contains genes encoding exfoliative toxin B, bacteriocin, and bacteriocin immunity [42]. Staphylococcal exfoliative toxins (ETs) are associated with strains isolated from patients with staphylococcal scaled-skin syndrome (SSSS) or bullous impetigo [43-45]. ET isoforms A, B and D are serine proteases that specifically cleave host desmoglein 1 , resulting in loss of cell-cell adhesion in the epidermal layer of skin, thereby causing blister formation and exfoliation $[43,46]$. In addition to pRW001, genes encoding exfoliative toxins are located on phages $(\varphi \mathrm{ETA}, \varphi \mathrm{ETA} 2$, and $\varphi \mathrm{ETA} 3)$, a genomic island $(v \mathrm{SA} \gamma$, former $e t d \mathrm{PI})$, and at least one other plasmid (pETB) (Table 2) [21, 42, 44, 45].

\section{Bacteriophages and virulence}

Bacteriophages (phages) or bacterial viruses seem to have the greatest impact on staphylococcal diversity and evolution. All phages are classified into one of three distinctive groups: lytic, temperate, and chronic. Lytic phages are members of the Myoviridae family that have been used in phage therapy, because bacteria lyse completely during release of progeny phages. Bacteria infected with chronic phages release progeny into the extracellular environment without killing the host, which allows bacteria to grow and divide. Temperate phages, which are members of the Siphoviridae family, form the most numerous group among all phages. Temperate phages have the ability to lyse bacteria after infection, but they typically form a long-term relationship with the host cell, whereby the phage DNA integrates into the staphylococcal genome as a prophage [47, 48]. Phages can impact expression of virulence determinants by either positive or negative lysogenic conversion. Following positive lysogenic conversion, bacteria express prophage-encoded virulence determinants. Negative lysogenic conversion occurs when there is insertional inactivation of genes (e.g., $\beta$-hemolysin of $S$. aureus) by integration of the phage DNA into the bacterial chromosome [47, 49]. Although there is loss of $\beta$-hemolysin during lysogeny, these prophages contain genes encoding immune-modulator proteins, such as staphylokinase (Sak), staphylococcal inhibitor of complement (SCIN), and chemotaxis inhibitory protein of $S$. aureus (CHIPS) [49, 50]. Other $S$. aureus prophages encode virulence molecules such as enterotoxins and Panton-Valentine leukocidin (PVL) (Table 2). PVL belongs to a group of bi-component, pore-forming cytolytic toxins that are specific for myeloid cells [51].

Prophages and prophage-encoded molecules also work in concert with other MGEs within staphylococci. For example, prophages create mobility for some staphylococcal pathogenicity islands. The most common example is the ability of helper phage $80 \alpha$ to mediate excision and transfer of SaPI1 to other staphylococci [52, 53]. Some phages also have the ability to transfer antibiotic resistance by transduction of plasmids or plasmid elements previously incorporated into chromosomal DNA. Plasmid pS194 with a chloramphenicol resistance determinant and pI258 containing erythromycin resistance are transduced by phages $\varphi 11$ and $\varphi 11 \mathrm{de}$, respectively [41].

\section{Pathogenicity islands}

Staphylococcal pathogenicity islands (SaPIs) are MGEs of 14-17 kb in size (Table 2). To date, at least 16 SaPIs have been sequenced and SaPI1 is considered as the prototype $[53,54]$. SaPIs form a coherent family with highly conserved core genes [53, 55]. Core genes include two open reading frames encoding transcriptional regulatory proteins and a region encoding intergrase, Rep protein, and terminase. In addition to core genes, almost all SaPIs encode enterotoxins or toxic shock syndrome toxin (TSST) [56]. SaPIbov2 is an exception to this rule, and instead contains Bap adhesion protein, which plays a role in bovine chronic mastitis infections [57, 58].

Staphylococcal pathogenicity islands are integrated in one of six different specific sites on the chromosome (att s and each is always in the same orientation [53]. SaPIs can be mobilized following infection by certain staphylococcal bacteriophages or by induction of endogenous prophages $[59,60]$, such as induced excision of SaPI1 by phage $80 \alpha$ [54]. Several hypotheses to explain the origin and evolution of SaPIs exist [56]. For example, Yarwood et al. [56] proposed the existence of a common ancestral genetic element-probably a prophage-for all SaPIs that then generated diversity of islands through modular recombination events.

\section{Genomic islands}

Three families of genomic islands exist among the S.aureus strains whose genomes have been sequenced [8, 13, 16, 61]. These genomic islands, named $v \mathrm{SA} \alpha, v \mathrm{SA} \beta$, and $v \mathrm{SA} \gamma$ (Table 2), are flanked by a broken transposase gene upstream and partial restriction-modification system (RM) type I downstream. Given the composition of genomic islands (remnant transposase genes and a $\mathrm{G}+\mathrm{C}$ content 
Table 1 Resistance determinants encoded on non-SCCmec staphylococcal MGEs

\begin{tabular}{|c|c|c|c|c|}
\hline MGE & Resistance determinant & Antibiotic/heavy metal & Mechanism of action & Reference \\
\hline \multirow[t]{23}{*}{ Plasmid } & $a a d D$ & $\begin{array}{l}\text { Neomycin, kanamycin, } \\
\text { paromomycin, and tobramycin }\end{array}$ & Aminoglycoside adenyltransferase & {$[100,101]$} \\
\hline & ant $4^{\prime}$ & Tobramycin & Aminoglycoside nucleotidyltransferase & [102] \\
\hline & $\operatorname{ars} R B C$ & Arsenate, antimonite & Efflux ATPase & {$[21,103,104]$} \\
\hline & blaZ, blaI, blaRl & Penicillin ( $\beta$-lactam antibiotics) & $\beta$-lactamase & {$[105,106]$} \\
\hline & ble & Bleomycin & $\begin{array}{l}\text { Bleomycin-binding protein prevents DNA } \\
\text { damage by binding bleomycin }\end{array}$ & {$[107,108]$} \\
\hline & $\operatorname{cad} A, B$ & $\begin{array}{l}\text { Cadmium resistance and probably } \\
\text { zinc }\end{array}$ & Cadmium efflux ATPase & {$[109,110]$} \\
\hline & $\operatorname{cad} D, X$ & Cadmium resistance & Efflux & {$[21,111]$} \\
\hline & cat & Chloramphenicol & Chloramphenicol acetyltransferase & {$[112,113]$} \\
\hline & $c f r$ & $\begin{array}{l}\text { Chloramphenicol, florfenicol, and } \\
\text { clindamycin }\end{array}$ & $\begin{array}{l}\text { Methylation of } 23 \mathrm{~S} \text { subunit of bacterial } \\
\text { ribosome }\end{array}$ & {$[114,115]$} \\
\hline & $d f r A, d f r K$ & Trimethoprim & Dihydrofolate reductase & {$[101,116]$} \\
\hline & $\operatorname{erm} B, C$ & $\begin{array}{l}\text { MLSB resistance (macrolides: } \\
\text { erythromycin, lincosamides: } \\
\text { clindamycin, streptogramin B) }\end{array}$ & $\begin{array}{l}\text { Methylation of } 23 \mathrm{~S} \text { subunit of bacterial } \\
\text { ribosome }\end{array}$ & {$[117,118]$} \\
\hline & fusB & Fusidic acid & Ribosome protection mechanism & {$[119,120]$} \\
\hline & ileS-2 & $\begin{array}{l}\text { High-level resistance to mupirocin } \\
\text { (pseudomonic acid A) }\end{array}$ & Isoleucyl RNA synthetase & {$[121,122]$} \\
\hline & mer operon & Mercury & Reduction of mercury ions to elementary $\mathrm{Hg}$ & [123] \\
\hline & mphBM & Macrolide antibiotics & Putative phosphorylase & [124] \\
\hline & $m s r A$ & Macrolide antibiotics & Active efflux & [124] \\
\hline & тирА & High-level mupirocin resistance & Novel isoleucyl RNA synthetase & {$[122,125]$} \\
\hline & $q a c A, B$ and $\operatorname{smr}(q a c C / D)$ & $\begin{array}{l}\text { Quaternary ammonium compounds, } \\
\text { biocides }\end{array}$ & Drug efflux pump & [126-128] \\
\hline & str & Streptomycin & Streptomycin adenyltransferase & [113] \\
\hline & tetK, tetL & Tetracyclines & Active efflux of tetracycline & [129-131] \\
\hline & vat & Streptogramins type A & Acetylation of the antibiotic & [132] \\
\hline & $v g a$ & $\begin{array}{l}\text { Streptogramins type } \mathrm{A} \text {, lincosamides, } \\
\text { and pleuromutilins }\end{array}$ & Efflux & {$[101]$} \\
\hline & $v g b$ & Streptogramins type B & Inactivation by virginiamycin B lyase & [133] \\
\hline \multirow[t]{10}{*}{ Transposon } & $a a c A-a p h D$ & Gentamycin, kanamycin, tobramycin & $\begin{array}{l}\text { Antibiotic modification by aminoglycoside } \\
\text { acetyltransferase and aminoglycoside } \\
\text { phosphotransferase }\end{array}$ & {$[82,86,90]$} \\
\hline & blaZ, blaI, blaRl & $\beta$-Lactam antibiotics & Hydrolysis of $\beta$-lactam ring & [134] \\
\hline & $\operatorname{cadB}, \operatorname{cad} C$ & Cadmium resistance & Efflux & [135] \\
\hline & $\operatorname{erm} A, B$ & $\begin{array}{l}\text { MLSB resistance (macrolides: } \\
\text { erythromycin, lincosamides: } \\
\text { clindamycin, streptogramin B) }\end{array}$ & $\begin{array}{l}\text { Methylation of } 23 \mathrm{~S} \text { subunit of bacterial } \\
\text { ribosome }\end{array}$ & [118] \\
\hline & fexA & Florfenicol, chloramphenicol & Efflux & [114] \\
\hline & merA, $B$ & $\begin{array}{l}\text { Respectively, inorganic and organic } \\
\text { mercury resistance }\end{array}$ & Ion transport & {$[89,136,137]$} \\
\hline & sat4 & Streptothricin & Streptothricin acetyltransferase & [115] \\
\hline & $\operatorname{spc}($ ant 9$)$ & Spectinomycin & Spectinomycin adenyltransferase & [102] \\
\hline & tetM & Tetracycline, minocycline & $\begin{array}{l}\text { Protection of ribosome binding site for } \\
\text { tetracycline }\end{array}$ & {$[129,131]$} \\
\hline & vanRSHAXYZ & Vancomycin & $\begin{array}{l}\text { Production of low affinity pepdydoglican } \\
\text { precursor with terminal D-Ala-D-Lac }\end{array}$ & {$[30,31,34,35,40]$} \\
\hline $\mathrm{SCC}_{476}$ & farl & Fusidic acid resistance & & [18] \\
\hline $\mathrm{SCC}_{\text {mercury }}$ & mer operon & Mercury & Ion transport & [69] \\
\hline
\end{tabular}

a Vancomycin resistance is encoded on the Tn1546 transposon but transferred by conjugative plasmid 
Table 2 S. aureus virulence determinant encoded on MGEs

\begin{tabular}{|c|c|c|c|}
\hline $\begin{array}{l}\text { Toxin/virulence determinant } \\
\text { (gene) }\end{array}$ & MGE & Disease/mechanism of action & Reference \\
\hline Adhesion protein Bap (bap) & SaPIbov2 & $\begin{array}{l}\text { Specific adhesion to bovine } \\
\text { mammary mucosa }\end{array}$ & {$[55]$} \\
\hline Bacteriocin (bsa) & $\nu \mathrm{SA} \beta$ & $\begin{array}{l}\text { Bactericidal activity against other } \\
\text { bacteria }\end{array}$ & [13] \\
\hline Capsular polysaccharide protein & SCCcapl & Inhibits phagocytosis & [75] \\
\hline $\begin{array}{l}\text { Chemotaxis inhibitory protein } \\
\text { of } S . \text { aureus (chip) }\end{array}$ & $\begin{array}{l}\varphi 13, \varphi \operatorname{tp} 310-3, \varphi \mathrm{N} 315, \varphi 252 \mathrm{~B}, \\
\varphi \mathrm{NM} 3, \varphi \mathrm{Mu} 3 \mathrm{~A}, \varphi \mathrm{Sa} 3 \mathrm{USA} 300, \\
\varphi \mathrm{Sa} 3 \mathrm{JH} 1, \varphi \mathrm{Sa} 3 \mathrm{mw}, \varphi \mathrm{Sa} 3 \mathrm{~ms}, \\
\varphi \mathrm{Sa} 3 \mathrm{JH} 9, \varphi \beta \mathrm{C}- \\
\text { USA300_TCH1516 }\end{array}$ & $\begin{array}{l}\text { Blocks C5a and fMLP-induced } \\
\text { neutrophil activation and } \\
\text { chemotaxis; blocks C5a and } \\
\text { formylated peptide receptor }\end{array}$ & {$[50,138]$} \\
\hline $\begin{array}{l}\text { Epidermal cell differentiation } \\
\text { inhibitor B }(\text { edin- } B)\end{array}$ & $v \mathrm{SA} \gamma(e t d \mathrm{PI})$ & $\begin{array}{l}\text { ADP-ribosyltransferase; inhibits } \\
\text { morphological differentiation of } \\
\text { keratinocytes in vitro and } \\
\text { modifies eukaryotic Rho } \\
\text { GTPase }\end{array}$ & [44] \\
\hline $\begin{array}{l}\text { Epidermal cell differentiation } \\
\text { inhibitor } \mathrm{C}(\text { edin- } C)\end{array}$ & pETB & $\begin{array}{l}\text { ADP-ribosyltransferase, inhibits } \\
\text { morphological differentiation of } \\
\text { keratinocytes in vitro and } \\
\text { modifies eukaryotic Rho } \\
\text { GTPase }\end{array}$ & [45] \\
\hline Exfoliative toxin A (eta) & $\varphi$ ETA, $\varphi$ ETA2, $\varphi$ ETA3 & $\begin{array}{l}\text { Causes staphylococcal scalded } \\
\text { skin syndrome (SSSS), Ritter } \\
\text { disease, and bulbous impetigo in } \\
\text { neonates }\end{array}$ & {$[21,44]$} \\
\hline Exfoliative toxin B $(e t b)$ & pETB, pRW001 & $\begin{array}{l}\text { Causes SSSS, Ritter disease, and } \\
\text { bulbous impetigo in neonates }\end{array}$ & {$[42,45]$} \\
\hline Exfoliative toxin D (etd) & $\nu \mathrm{SA} \gamma(e t d \mathrm{PI})$ & $\begin{array}{l}\text { Causes SSSS, Ritter disease, and } \\
\text { bulbous impetigo in neonates }\end{array}$ & {$[44,45]$} \\
\hline Enterotoxin A (sea) & $\begin{array}{l}\varphi \mathrm{Sa} 3 \mathrm{~ms}, \varphi \mathrm{Sa} 3, \varphi \mathrm{Sa} 3 \mathrm{mw}, \\
\varphi 252 \mathrm{~B}, \varphi \mathrm{NM} 3, \varphi \mathrm{Mu} 50 \mathrm{~A},\end{array}$ & $\begin{array}{l}\text { Super antigen (SAg), causes food } \\
\text { poisoning }\end{array}$ & [13] \\
\hline Enterotoxin B (seb) & SaPI1, SaPI3,pZA10 & SAg, causes food poisoning & {$[13,139,140]$} \\
\hline Enterotoxin $\mathrm{C}(\mathrm{sec})$ & SaPIbov1 & SAg, causes food poisoning & {$[13,141]$} \\
\hline Enterotoxin $\mathrm{C} 1(\mathrm{sec} 1)$ & SaPI4, pZA10 & SAg, causes food poisoning & {$[13,139]$} \\
\hline Enterotoxin $\mathrm{C} 3(\sec 3)$ & SaPIn1/m1 & SAg, causes food poisoning & {$[13]$} \\
\hline Enterotoxin C4 (sec4) & SaPImw2, SaPIm3 & SAg, causes food poisoning & {$[13]$} \\
\hline Enterotoxin D (sed) & pIB485 & SAg, causes food poisoning & {$[142]$} \\
\hline Enterotoxin G (seg) & $\varphi \mathrm{Sa} 3, v \mathrm{SA} \beta(\mathrm{SaPIn} 3 / \mathrm{m} 3)$ & SAg, causes food poisoning & [13] \\
\hline Enterotoxin I (sei) & $\nu \mathrm{SA} \beta(\mathrm{SaPIn} 3 / \mathrm{m} 3)$ & SAg, causes food poisoning & {$[13]$} \\
\hline Enterotoxin $\mathrm{J}$ (sej) & pIB485 & SAg, causes food poisoning & [143] \\
\hline Enterotoxin K (sek) & $\begin{array}{l}\varphi \mathrm{Sa} 3 \mathrm{~ms}, \varphi \mathrm{Sa} 3 \mathrm{mw}, \mathrm{SaPIbov} 1 \\
\text { SaPI1, SaPI3, SaPI5 }\end{array}$ & SAg, causes food poisoning & {$[56,144]$} \\
\hline Enterotoxin K2 (sek2) & $\varphi \mathrm{Sa} 3$ & SAg, causes food poisoning & {$[145]$} \\
\hline Enterotoxin L ( $\mathrm{sel})$ & $\begin{array}{l}\text { SaPI1, SaPIbov1, SaPI3, } \\
\text { SaPIn1/m1, SaPI4 }\end{array}$ & SAg, causes food poisoning & {$[54,55,144]$} \\
\hline Enterotoxin L2 (sel2) & SaPImw2, SaPIm3, & SAg, causes food poisoning & [13] \\
\hline Enterotoxin M (sem) & $\nu \mathrm{SA} \beta(\operatorname{SaPIn} 3 / \mathrm{m} 3)$ & SAg, causes food poisoning & [13] \\
\hline Enterotoxin N (sen) & $\nu \mathrm{SA} \beta(\mathrm{SaPIn} 3 / \mathrm{m} 3)$ & SAg, causes food poisoning & {$[13,146]$} \\
\hline Enterotoxin O (seo) & $\nu \mathrm{SA} \beta(\operatorname{SaPIn} 3 / \mathrm{m} 3)$ & SAg, causes food poisoning & [13] \\
\hline Enterotoxin P (sep) & $\varphi \mathrm{N} 315, \varphi \mathrm{Mu} 50 \mathrm{~A}$ & SAg, causes food poisoning & {$[146,147]$} \\
\hline Enterotoxin Q (seq) & $\begin{array}{l}\varphi \mathrm{Sa} 3 \mathrm{~ms}, \varphi \mathrm{Sa} 3 \mathrm{mw}, \mathrm{SaPI} 1, \mathrm{SaPI} 3, \\
\quad \mathrm{SaPI} 5\end{array}$ & SAg, causes food poisoning & [56] \\
\hline Ferrichrome operon $(f h u D)$ & SaPI3, SaPIm4 & Iron up-take & [148] \\
\hline$\alpha$-hemolysin (hla) & $v \mathrm{SA} \gamma(e t d \mathrm{PI})$ & Pore-forming cytolytic toxin & {$[149,150]$} \\
\hline
\end{tabular}


Table 2 continued

\begin{tabular}{|c|c|c|c|}
\hline $\begin{array}{l}\text { Toxin/virulence determinant } \\
\text { (gene) }\end{array}$ & MGE & Disease/mechanism of action & Reference \\
\hline Hyaluronate lyase (hysA) & $\nu \mathrm{SA} \beta$ & $\begin{array}{l}\text { Degradation of } \\
\text { mucopolysaccharide hyaluronic } \\
\text { acid }\end{array}$ & {$[13,151]$} \\
\hline Leukocidin $(l u k M, l u k F)$ & $\varphi \mathrm{PV} 83$ & Pore-forming leukocyte toxin & {$[152]$} \\
\hline Leukotoxin D, E (lukD, lukE) & $\nu \mathrm{SA} \beta$ & Pore-forming leukocyte toxin & {$[13,153]$} \\
\hline Lipoprotein-like $(l p l)$ & $\nu \mathrm{SA} \alpha$ & $\begin{array}{l}\text { Induce inflammatory response of } \\
\text { host immune system }\end{array}$ & {$[13,65]$} \\
\hline Lysophospholipase & pAvX (poultry strains) & Hypothetical role in virulence & [99] \\
\hline $\begin{array}{l}\text { Pantone-Valentine leukocidin } \\
\quad(l u k F-P V, l u k S-P V)\end{array}$ & $\begin{array}{l}\varphi \mathrm{Sa} 2 \mathrm{mw}, \varphi \mathrm{PVL} 108, \varphi \mathrm{Sa} 2, \\
\varphi \mathrm{Sa} 2 \mathrm{USA} 300, \varphi \mathrm{SLT}, \varphi \mathrm{PVL}, \\
\varphi \mathrm{SLT}-\mathrm{USA} 300 \_\mathrm{TCH} 1516, \\
\varphi \operatorname{tp} 310-1, \varphi 2958 \mathrm{PVL}\end{array}$ & $\begin{array}{l}\text { Pore-forming leukocyte toxin, } \\
\text { linked by epidemiology to } \\
\text { necrotic infections }\end{array}$ & {$[154-158]$} \\
\hline Pathogenicity island protein (ear) & $\begin{array}{l}\text { SaPImw2; SaPI1, SaPI3, SaPI4, } \\
\text { SaPI5 }\end{array}$ & Unknown & {$[54]$} \\
\hline $\begin{array}{l}\text { Phenol-soluble modulin located } \\
\text { within SCCmec (psm-mec) }\end{array}$ & $\mathrm{SCCmec}$ & $\begin{array}{l}\text { Pro-inflammatory and cytolytic } \\
\text { activity }\end{array}$ & [159] \\
\hline Phenol-soluble modulins $(p s m \beta)$ & $\nu \mathrm{SA} \gamma(e t d \mathrm{PI})$ & Possible pro-inflammatory activity & {$[16,160,161]$} \\
\hline $\begin{array}{l}\text { Plasmin-sensitive surface protein } \\
\quad(p l s)\end{array}$ & SCCmec I & $\begin{array}{l}\text { Decreases the invasiveness of } \\
\text { MRSA strains, acts as an } \\
\text { adhesin }\end{array}$ & {$[162]$} \\
\hline Serine protease-like protein $(s p l)$ & $\nu \mathrm{SA} \beta(\mathrm{SaPIn} 3 / \mathrm{m} 3)$ & Hypothetical role in virulence & {$[13,163]$} \\
\hline Staphopain A ( $s c p A)$ & $\mathrm{pAvX}$ & $\begin{array}{l}\text { Edematous and necrotic dermatitis } \\
\text { in chickens }\end{array}$ & {$[99,164]$} \\
\hline $\begin{array}{l}\text { Staphylococcal inhibitor of } \\
\text { complement }(s c n)\end{array}$ & $\begin{array}{l}\varphi 13, \varphi \operatorname{tp} 310-3, \varphi \mathrm{N} 315, \varphi \mathrm{Sa} 3 \mathrm{mw}, \\
\varphi 252 \mathrm{~B}, \varphi \mathrm{NM} 3, \varphi \mathrm{Mu} 50 \mathrm{~A}, \\
\varphi \mathrm{Sa} 3 \mathrm{JH} 1, \varphi \mathrm{Sa} 3 \mathrm{~ms}, \varphi \mathrm{Sa} 3 \mathrm{JH} 9 \\
\varphi \mathrm{Mu} 3 \mathrm{~A}, \varphi \mathrm{Sa} 3 \mathrm{USA} 300, \\
\varphi \beta \mathrm{C}-\mathrm{USA} 300 \_\mathrm{TCH} 1516\end{array}$ & $\begin{array}{l}\text { Inhibits phagocytosis of } S \text {. aureus } \\
\text { by human neutrophils; blocks } \\
\text { formation of } \mathrm{C} 3 \mathrm{~b}\end{array}$ & {$[50,165]$} \\
\hline $\begin{array}{l}\text { Staphylococcal superantigen-like, } \\
\text { SSL (former, staphylococcal } \\
\text { enterotoxin-like, set) }\end{array}$ & $v \mathrm{SA} \alpha(\mathrm{SaPIn} 2 / \mathrm{m} 2)$ & $\begin{array}{l}\text { Targeting elements of innate } \\
\text { immune response }\end{array}$ & {$[13,166]$} \\
\hline Staphylokinase $(s a k)$ & $\begin{array}{l}\varphi \mathrm{N} 315, \varphi \mathrm{Mu} 50 \mathrm{~A}, \varphi \mathrm{Sa} 2, \\
\varphi \mathrm{Sa} 3 \mathrm{mw}, \varphi 6390, \varphi 13, \varphi 252 \mathrm{~B}, \\
\varphi \mathrm{NM} 3, \varphi \mathrm{Mu} 3 \mathrm{~A}, \varphi \mathrm{Sa} 3 \mathrm{~ms}, \\
\varphi \operatorname{tp} 310-3, \varphi \beta \mathrm{C}- \\
\text { USA300_TCH1516, } \\
\varphi \mathrm{Sa} 3 \mathrm{USA} 300 \varphi \mathrm{Sa} 3 \mathrm{JH} 1, \\
\varphi \mathrm{Sa} 3 \mathrm{H} 9,\end{array}$ & $\begin{array}{l}\text { Proteolytic destruction of host } \\
\text { tissue; activates conversion of } \\
\text { plasminogen to plasmin; inhibits } \\
\text { opsonization by degradation of } \\
\text { IgG and C3b, promotes } \\
\text { resistance to defensins }\end{array}$ & {$[147,167-169]$} \\
\hline TSST-1 $(t s t)$ & $\begin{array}{l}\text { SaPI1, SaPI2, SaPIbov1, SaPI3, } \\
\text { SaPIn1/m1 }\end{array}$ & $\begin{array}{l}\text { Causes toxic shock syndrome } \\
\text { (TSS) }\end{array}$ & {$[46,55,170,171]$} \\
\hline
\end{tabular}

Genomic islands: $v \mathrm{SA} \alpha, v \mathrm{SA} \beta$, and $\nu \mathrm{SA} \gamma$ (etdPI)

Pathogenicity islands: SaPIbov1 and SaPIbov2, SaPI1- SaPI5, SaPIn1/m1, SaPIn3/m3, SaPImw2, SaPIm3, and SaPIm4

Phages: $\varphi 13, \varphi \operatorname{tp} 310-3, \varphi \mathrm{N} 315, \varphi \mathrm{Sa} 3, \varphi \mathrm{Sa3mw}, \varphi 252 \mathrm{~B}, \varphi \mathrm{NM} 3, \varphi \mathrm{Mu} 50 \mathrm{~A}, \varphi \mathrm{Sa3JH} 1, \varphi \mathrm{Sa} 3 \mathrm{~ms}, \varphi \mathrm{Sa} 3 \mathrm{JH} 9, \varphi \mathrm{Mu} 3 \mathrm{~A}, \varphi \mathrm{Sa} 3 \mathrm{USA} 300, \varphi \beta \mathrm{C}-$ USA300_TCH1516, $\varphi$ ETA, $\varphi$ ETA2, $\varphi$ ETA3, $\varphi$ PV83, $\varphi$ PVL108, $\varphi$ SLT, $\varphi$ PVL, $\varphi$ SLT-USA300_TCH1516, $\varphi$ tp310-1, and $\varphi 2958$ PVL

Plasmids: pAvX, pIB485, pZA10, pETB, and pRW001

SCC Staphylococcal cassette chromosome

that differs from the core genome), a current notion is that genomic islands were once mobile elements acquired by HGT [62]. A complete RM type I comprises host specificity determinant genes $h s d R$, $h s d M$, and $h s d S$, but only $h s d M$ and $h s d S$ are found juxtaposed to the $S$. aureus genomic islands $[13,61,63]$. Both flanking DNA segments contribute to the stability of genomic islands within the $S$. aureus chromosome. A lipoprotein gene cluster $(l p l)$ and staphylococcal superantigen-like genes ( $s s l)$ are located on $v \mathrm{SA} \alpha$ [64]. $v \mathrm{SA} \beta$ (also known as $\mathrm{SaPIn} 3 / \mathrm{m} 3$ ) encodes bacteriocin, enterotoxins, hyaluronate lyase, and a serine protease gene cluster $[13,18,65]$. The third staphylococcal 


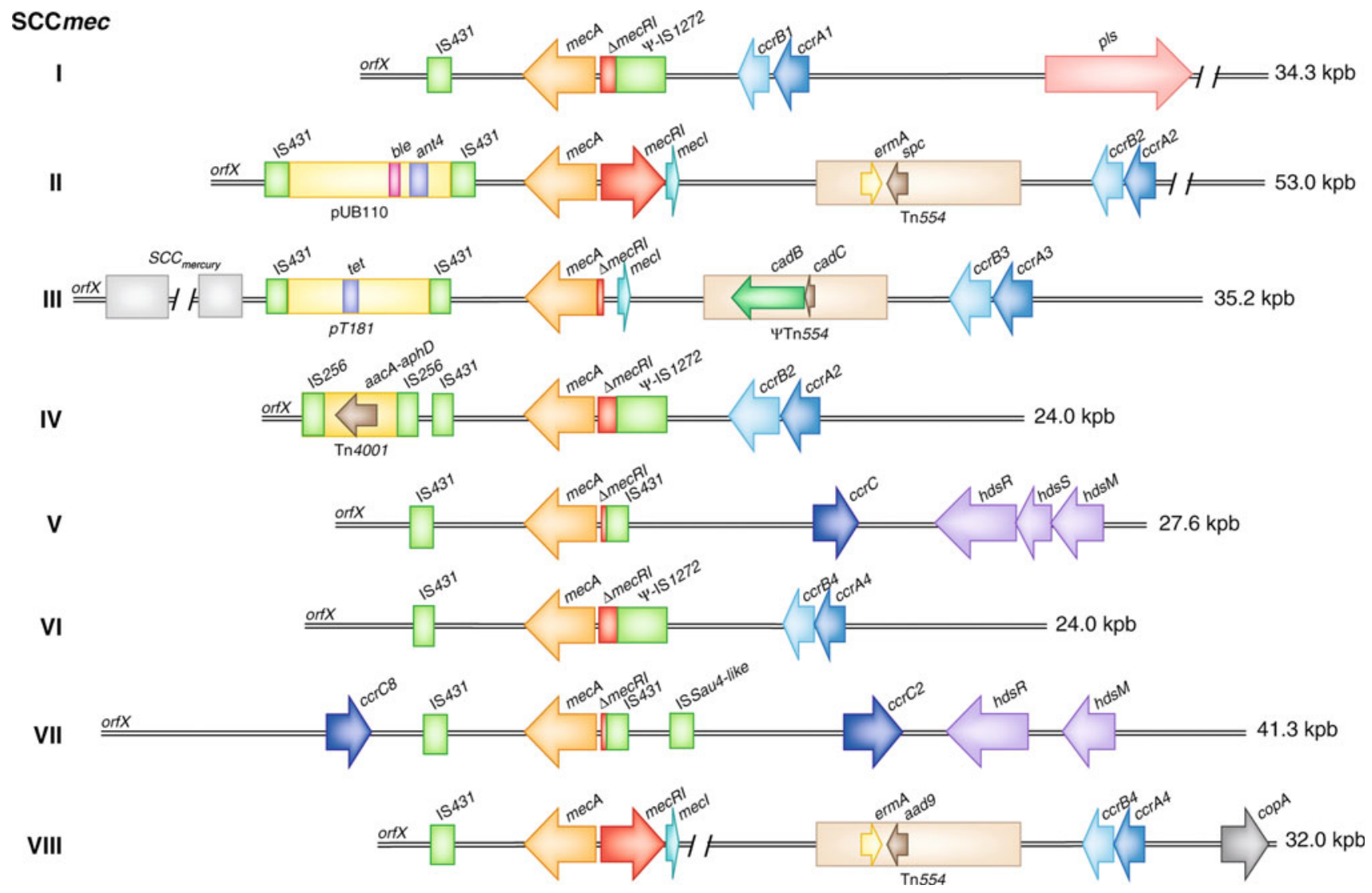

Fig. 4 Comparison of $S$. aureus SCCmec types. Class A SCCmec contains a complete mecA regulon (mecl-mecRl-mecA). Class B and class $\mathrm{C}$ SCCmec contain regulatory genes that are disrupted by

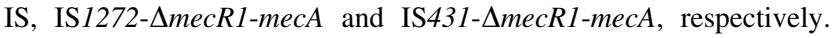
Tn554 encodes erythromycin (ermA) and streptomycin/spectinomycin resistance ( $a a d 9$ or $s p c$ ); copA encodes a putative copper-transport

genomic island, $\nu \mathrm{SA} \gamma$, contains genes encoding $\beta$-type phenol-soluble modulins and a cluster of $s s l$ genes similar to that present within $v \mathrm{SA} \alpha[16]$.

\section{Staphylococcal cassette chromosome}

Staphylococcal cassette chromosomes (SCCs) are relatively large fragments of DNA that always insert into the orf $X$ gene on the $S$. aureus chromosome. SCC can encode antibiotic resistance and/or virulence determinants. Considering that many SCCs encode the methicillin resistance gene (mecA), SCCs can be classified into staphylococcal cassette chromosome mec (SCCmec) or non-SCCmec groups.

\section{$\mathrm{SCCmec}$}

The first MRSA strain was reported in 1961, 2 years after the introduction of methicillin for treatment of penicillinresistant $S$. aureus infections [12, 66]. All MRSA strains
ATPase; $h s d R, h s d M$, and $h s d S$ encode a partial restriction-modification system (RM) type I; Tn4001 encodes an aminoglycoside resistance operon $(a a c A-a p h D)$; plasmid pT181 encodes tetracycline resistance (tet); $\Psi$ Tn554 encodes cadmium resistance ( $c a d B, c a d C$ ); and plasmid pUB110 encodes bleomycin (ble) and tobramycin resistance $\left(a n t 4^{\prime}\right)$. pls Plasmin-sensitive surface protein

contain SCCmec, which encodes the mecA gene, thus conferring resistance to methicillin and all $\beta$-lactam antibiotics (reviewed in [12]). SCCmec may have been acquired by $S$. aureus from $S$. sciuri $[67,68]$. Resistance to $\beta$-lactam antibiotics is maintained by production of a lowaffinity penicillin-binding protein (PBP2a), which fails to bind methicillin and other $\beta$-lactam antibiotics. As a result, these antibiotics do not inhibit the ability of PBPs (transpeptidase enzymes) to cross-link peptidoglycan polymers of the bacterial cell wall. In addition to the mecA gene, SCCmec encodes the repressor MecI, transmembrane $\beta$-lactam signal transducer MecR1, recombinases CcrAB and $\mathrm{CcrC}$, and joining (formerly junkyard) regions $\mathrm{J}$, which may also encode additional antibiotic resistance (Fig. 4). Integration and excision of SCCmec by the recombinases occurs within a specific attachment site (attBscc) on the $S$. aureus chromosome at the $3^{\prime}$ end of orfX [61].

Based on the organization of mec and associated genes within the SCCmec complex, five (A-E) different classes of SCCmec have been defined, of which three $(\mathrm{A}-\mathrm{C})$ are the most common in S. aureus [69-71]. Only class A 
SCCmec consists of the complete mecA regulon (mecl$m e c R 1-m e c A$ ), as the regulatory genes are disrupted by insertional sequences in class B and C, SCCmec-IS1272$\Delta m e c R 1-m e c A$ in class B and IS431- $\Delta m e c R 1-m e c A$ in class C SCCmec elements [61, 70]. Three classes of the mec complex and four different $c c r$ allotypes define at present eight SCCmec types (I-VIII) (Fig. 4). However, SCCmec types can be further differentiated into subtypes depending on variations in the $\mathrm{J}$ regions. Interestingly, communityassociated MRSA (CA-MRSA) strains typically carry SCCmecIV, V, or VII elements [72], whereas HA-MRSA typically contain the larger SCCmecI, II, III, VI, or VIII elements that may encode resistance determinants in addition to mec $A[12,13,69,72]$. These additional resistance determinants are often encoded by plasmids, transposons, or insertion sequences incorporated into the $\mathrm{J}$ regions of SCCmec [61]. For example, the J1 region of SCCmec VIII encodes a putative copper-transport ATPase (copA) and the $\mathrm{J} 2$ region has a $\mathrm{Tn} 554$ transposon encoding erythromycin (ermA) and streptomycin/spectinomycin resistance (aad9) genes (for more details, see Table 1; Fig. 4) [73, 74].

\section{Non-mec SCC}

Staphylococcal cassette chromosomes can be complex and are thus not limited to encoding methicillin resistance. Non-mec SCC and $\psi \mathrm{SCC}$ (without or no functional recombinase) contain virulence or fitness/survival determinants. A methicillin-susceptible $S$. aureus strain, MSSA476, contains a mec-like element $\left(\mathrm{SCC}_{476}\right)$ that encodes fusidic acid resistance [18]. SCCmercury encodes resistance to mercury chloride that was probably obtained from coagulase-negative staphylococci (CoNS) by integration of a plasmid that carried the resistance determinant or by direct transfer of the SCCmercury element [69].

Some $S$. aureus strains produce capsular polysaccharide 1 , which has been reported to confer resistance to phagocytosis [75]. The genes encoding synthesis of capsular polysaccharide 1 are located on a special SCC element named SCCcapl [75]. Although SCCcapI resembles type III of SCCmec, it is immobile because it lacks an active $\operatorname{ccr} A$ homologue and the $\operatorname{ccr} B$ homologue contains a nonsense mutation [75, 76].

\section{Arginine catabolic mobile element}

The arginine catabolic mobile element (ACME) was discovered by sequencing the complete genome of USA300, the most prominent CA-MRSA strain of North America [15]. ACME encodes a complete arginine deiminase pathway that converts L-arginine to carbon dioxide, ATP, and ammonia. A cluster of six genes, $\operatorname{arcRADBC}$ (arc locus) and opp3 (oligopeptide permease system), constitute type I ACME present in the USA300 strain [15]. Type I ACME is associated with specific SCCmec subtypes (Fig. 3). It is present in clinical isolates belonging to multilocus sequence type (MLST or ST) 8 containing SCCmecIVa, but not in SCCmecIVb, IVc, or IVmisc [77]. An ACME variant that lacks the opp3 operon and varies in DNA sequence has also been found in ST8 MSSA, ST5 (USA100, SCCmecII), and ST59 (USA1000) strains [77-79]. An ACME variant has also been detected in MRSA ST97 strains carrying SCCmecV [77].

The arc cluster contained within ACME is distinct from the other $S$. aureus arc cluster encoded within the core genome [15]. ACME is adjacent to SCCmec and integrated at the same $a t t B$ site within $\operatorname{orf} X$ [15]. Therefore, it is likely that the recombinases that mediate excision of SCCmec also mobilize ACME [15, 80].

The role played by ACME in the success of USA300 remains unknown. Diep et al. suggest it enhances fitness of $S$. aureus, possibly by facilitating colonization and/or hematogenous dissemination to target organs $[15,80]$. On the other hand, Montgomery et al. [81] found no significant difference between ACME-positive and ACME-negative USA300 strains in a rat model of necrotizing pneumonia and a mouse model of skin infection. Further studies are needed to better understand the importance of this interesting MGE.

\section{Other transposable elements}

Both insertion sequences (IS) and transposons (Tn) are widely distributed among the $S$. aureus genome. They may be present in a single copy or multiple copies on the chromosome or in association with other MGEs.

Insertion sequences

Although insertion sequences (IS) can exist independently in the $S$. aureus genome, they often present as pairs constituting a composite transposon [82]. IS insert into various loci and may cause changes in the expression of genes in the core chromosome. In addition, IS inactivate genes by direct insertion or by having a polar effect on the transcription of nearby genes [83, 84]. Activation of genes within the vicinity of an IS is usually mediated by promoters carried by IS elements or by forming a hybrid promoter with the native promoter of particular gene [85]. IS256 and IS257, in addition to constituting composite transposons $\operatorname{Tn} 4001$ and $\operatorname{Tn} 4003$, form a hybrid promoter for the aminoglycoside resistance operon $(a a c A-a p h D)$ and the gene encoding resistance to trimethoprim ( $d f r A)$, respectively $[82,86,87]$. 


\section{Transposons}

Transposons (Tn) predominantly encode antibiotic resistance genes in S. aureus (Table 1). The smaller transposons are usually presented in multiple copies in the staphylococcal genome, either inserted into the chromosome or into MGEs, such as SCC or plasmids. This group includes Tn554 and Tn552, which encode resistance to MLS $_{\mathrm{B}}$ antibiotics and spectinomycin or penicillinase, respectively $[41,61,88]$.

By comparison, larger transposons $(>18 \mathrm{kbp})$ are present in single copies and encode resistance to antibiotics such as tetracycline [89], trimethoprim [87], aminoglycosides [82, 90], or vancomycin [30, 31, 35].

\section{Concluding remarks}

A wide range of environmental conditions, including interspecies competition within particular ecological niche and antibiotic selective pressure, select for organisms that have acquired MGEs - those that are presumably advantageous for survival-by HGT. Production of antibiotics by microorganisms is mirrored (countered) by development of resistance to these molecules and is a naturally occurring phenomenon. Antibiotics are toxins produced by bacteria and fungi to compete with other microorganisms for a specific ecological niche. Unfortunately, the level of antibiotic resistance among bacteria continues to increase, consistent with the high use of antibiotics by humans. Sub-inhibitory concentrations of antibiotics also create an environment conducive to acquisition of resistance [91].

Antibiotics that interfere with bacterial DNA replication and induce an SOS response also induce excision and transduction of prophages and staphylococcal pathogenicity islands in the bacterial genome, resulting in highfrequency of horizontal gene transfer [60, 92, 93]. Consequentially, this process promotes dissemination of determinants encoding antibiotic resistance molecules and virulence factors. MGEs can be species-specific, and, therefore, differences exist in MGEs of $S$. aureus strains that have a tropism for humans or animals [94]. Nevertheless, some $S$. aureus strains transmit from animals to humans or vice versa [95-98]. Transfer of staphylococci from one host species to another provides an additional means to acquire new genetic material, often encoded by MGEs [99].

In summary, although MGEs constitute only $\sim 25 \%$ of the staphylococcal genome [8], they encode many putative virulence factors and antibiotic determinants and thus play an important role in bacterial adaptability and survival.
Acknowledgments We thank James M. Musser (The Methodist Hospital Research Institute, Houston TX, USA) for critical reading of the manuscript. This article was supported by the Intramural Research Program of the National Institute of Allergy and Infectious Diseases, National Institutes of Health.

Open Access This article is distributed under the terms of the Creative Commons Attribution Noncommercial License which permits any noncommercial use, distribution, and reproduction in any medium, provided the original author(s) and source are credited.

\section{References}

1. McClintock B (1950) The origin and behavior of mutable loci in maize. Proc Natl Acad Sci USA 36:344-355

2. McClintock B (1951) Chromosome organization and genetic expression. Cold Spring Harb Symp Quant Biol 16:13-47

3. Frost LS, Leplae R, Summers AO, Toussaint A (2005) Mobile genetic elements: the agents of open source evolution. Nat Rev Microbiol 3:722-732

4. Siefert JL (2009) Defining the mobilome. Methods Mol Biol 532:13-27

5. Jain R, Rivera MC, Lake JA (1999) Horizontal gene transfer among genomes: the complexity hypothesis. Proc Natl Acad Sci USA 96:3801-3806

6. Keeling PJ, Palmer JD (2008) Horizontal gene transfer in eukaryotic evolution. Nat Rev Genet 9:605-618

7. Hacker J, Kaper JB (2000) Pathogenicity islands and the evolution of microbes. Annu Rev Microbiol 54:641-679

8. Lindsay J, Holden M (2004) Staphylococcus aureus: superbug, super genome? Trends Microbiol 12:378-385

9. DeLeo FR, Chambers HF (2009) Reemergence of antibioticresistant Staphylococcus aureus in the genomics era. J Clin Invest 119:2464-2474

10. van Belkum A (2006) Staphylococcal colonization and infection: homeostasis versus disbalance of human (innate) immunity and bacterial virulence. Curr Opin Infect Dis 19:339-344

11. Weems JJ (2001) The many faces of Staphylococcus aureus infection. Recognizing and managing its life-threatening manifestations. Postgrad Med 110:24-26, 29-31, 35-36

12. Chambers HF, DeLeo FR (2009) Waves of resistance: Staphylococcus aureus in the antibiotic era. Nat Rev Microbiol 7:629-641

13. Baba T, Takeuchi F, Kuroda M, Yuzawa H, Aoki K-I, Oguchi A, Nagai Y, Iwama N, Asano K, Naimi T, Kuroda H, Cui L, Yamamoto K, Hiramatsu K (2002) Genome and virulence determinants of high virulence community-acquired MRSA. Lancet 359:1819-1827

14. Baba T, Bae T, Schneewind O, Takeuchi F, Hiramatsu K (2008) Genome sequence of Staphylococcus aureus strain Newman and comparative analysis of staphylococcal genomes: polymorphism and evolution of two major pathogenicity islands. J Bacteriol 190:300-310

15. Diep B, Gill S, Chang R, Phan T, Chen J, Davidson M, Lin F, Lin J, Carleton H, Mongodin E, Sensabaugh G, PerdreauRemington F (2006) Complete genome sequence of USA300, an epidemic clone of community-acquired meticillin-resistant Staphylococcus aureus. Lancet 367:731-739

16. Gill SR, Fouts DE, Archer GL, Mongodin EF, DeBoy RT, Ravel J, Paulsen IT, Kolonay JF, Brinkac L, Beanan M, Dodson RJ, Daugherty SC, Madupu R, Angiuoli SV, Durkin AS, Haft DH, Vamathevan J, Khouri H, Utterback T, Lee C, Dimitrov G, Jiang L, Qin H, Weidman J, Tran K, Kang K, Hance IR, Nelson KE, 
Fraser CM (2005) Insights on evolution of virulence and resistance from the complete genome analysis of an early methicillin-resistant Staphylococcus aureus strain and a biofilmproducing methicillin-resistant Staphylococcus epidermidis strain. J Bacteriol 187:2426-2438

17. Herron-Olson L, Fitzgerald JR, Musser JM, Kapur V (2007) Molecular correlates of host specialization in Staphylococcus aureus. PLoS One 2:e1120

18. Holden MTG, Feil EJ, Lindsay JA, Peacock SJ, Day NPJ, Enright MC, Foster TJ, Moore CE, Hurst L, Atkin R, Barron A, Bason N, Bentley SD, Chillingworth C, Chillingworth $\mathrm{T}$, Churcher C, Clark L, Corton C, Cronin A, Doggett J, Dowd L, Feltwell T, Hance Z, Harris B, Hauser H, Holroyd S, Jagels K, James KD, Lennard N, Line A, Mayes R, Moule S, Mungall K, Ormond D, Quail MA, Rabbinowitsch E, Rutherford K, Sanders M, Sharp S, Simmonds M, Stevens K, Whitehead S, Barrell BG, Spratt BG, Parkhill J (2004) Complete genomes of two clinical Staphylococcus aureus strains: evidence for the rapid evolution of virulence and drug resistance. Proc Natl Acad Sci USA 101:9786-9791

19. Holden MT, Lindsay JA, Corton C, Quail MA, Cockfield JD, Pathak S, Batra R, Parkhill J, Bentley SD, Edgeworth JD (2010) Genome sequence of a recently emerged, highly transmissible, multi-antibiotic- and antiseptic-resistant variant of methicillinresistant Staphylococcus aureus, sequence type 239 (TW). J Bacteriol 192:888-892

20. Kennedy AD, Otto M, Braughton KR, Whitney AR, Chen L, Mathema B, Mediavilla JR, Byrne KA, Parkins LD, Tenover FC, Kreiswirth BN, Musser JM, DeLeo FR (2008) Epidemic community-associated methicillin-resistant Staphylococcus aureus: recent clonal expansion and diversification. Proc Natl Acad Sci USA 105:1327-1332

21. Kuroda M, Ohta T, Uchiyama I, Baba T, Yuzawa H, Kobayashi I, Cui L, Oguchi A, Aoki K-I, Nagai Y, Lian J, Ito T, Kanamori M, Matsumaru H, Maruyama A, Murakami H, Hosoyama A, Mizutani-Ui Y, Takahashi NK, Sawano T, Inoue R-I, Kaito C, Sekimizu K, Hirakawa H, Kuhara S, Goto S, Yabuzaki J, Kanehisa M, Yamashita A, Oshima K, Furuya K, Yoshino C, Shiba T, Hattori M, Ogasawara N, Hayashi H, Hiramatsu K (2001) Whole genome sequencing of meticillin-resistant Staphylococcus aureus. Lancet 357:1225-1240

22. Musser JM, Kapur V (1992) Clonal analysis of methicillinresistant Staphylococcus aureus strains from intercontinental sources: association of the mec gene with divergent phylogenetic lineages implies dissemination by horizontal transfer and recombination. J Clin Microbiol 30:2058-2063

23. Berg T, Firth N, Apisiridej S, Hettiaratchi A, Leelaporn A, Skurray RA (1998) Complete nucleotide sequence of pSK41: evolution of staphylococcal conjugative multiresistance plasmids. J Bacteriol 180:4350-4359

24. Khan SA (2005) Plasmid rolling-circle replication: highlights of two decades of research. Plasmid 53:126-136

25. Lindsay JA (2010) Genomic variation and evolution of Staphylococcus aureus. Int J Med Microbiol 300:98-103

26. Morikawa K, Inose $\mathrm{Y}$, Okamura $\mathrm{H}$, Maruyama A, Hayashi H, Takeyasu K, Ohta TA (2003) New staphylococcal sigma factor in the conserved gene cassette: functional significance and implication for the evolutionary processes. Gen Cell 8:699-712

27. Olsen JE, Christensen H, Aarestrup FM (2006) Diversity and evolution of blaZ from Staphylococcus aureus and coagulasenegative staphylococci. J Antimicrob Chemother 57:450-460

28. Hackbarth CJ, Chambers HF (1993) blaI and blaR1 regulate beta-lactamase and PBP 2a production in methicillin-resistant Staphylococcus aureus. Antimicrob Agents Chemother 37:1144-1149
29. Sidhu MS, Heir E, Leegaard T, Wiger K, Holck A (2002) Frequency of disinfectant resistance genes and genetic ginkage with B-lactamase transposon Tn552 among clinical staphylococci. Antimicrob Agents Chemother 46:2797-2803

30. Weigel LM, Clewell DB, Gill SR, Clark NC, McDougal LK, Flannagan SE, Kolonay JF, Shetty J, Killgore GE, Tenover FC (2003) Genetic analysis of a high-level vancomycin-resistant isolate of Staphylococcus aureus. Science 302:1569-1571

31. Zhu W, Clark NC, McDougal LK, Hageman J, McDonald LC, Patel JB (2008) Vancomycin-resistant Staphylococcus aureus isolates associated with inc18-like vanA plasmids in Michigan. Antimicrob Agents Chemother 52:452-457

32. Mwangi MM, Wu SW, Zhou Y, Sieradzki K, de Lencastre H, Richardson P, Bruce D, Rubin E, Myers E, Siggia ED, Tomasz A (2007) Tracking the in vivo evolution of multidrug resistance in Staphylococcus aureus by whole-genome sequencing. Proc Natl Acad Sci USA 104:9451-9456

33. Hiramatsu K (2001) Vancomycin-resistant Staphylococcus aureus: a new model of antibiotic resistance. Lancet Infect Dis 1:147-155

34. Pantosti A, Sanchini A, Monaco M (2007) Mechanisms of antibiotic resistance in Staphylococcus aureus. Future Microbiol 2:323-334

35. Ballard SA, Pertile KK, Lim M, Johnson PDR, Grayson ML (2005) Molecular characterization of vanB elements in naturally occurring gut anaerobes. Antimicrob Agents Chemother 49:1688-1694

36. Perichon B, Courvalin P (2009) VanA-type vancomycin-resistant Staphylococcus aureus. Antimicrob Agents Chemother 53:4580-4587

37. Tenover FC, Weigel LM, Appelbaum PC, McDougal LK, Chaitram J, McAllister S, Clark N, Killgore G, O'Hara CM, Jevitt L, Patel JB, Bozdogan B (2004) Vancomycin-resistant Staphylococcus aureus isolate from a patient in Pennsylvania. Antimicrob Agents Chemother 48:275-280

38. Saha B, Singh AK, Ghosh A, Bal M (2008) Identification and characterization of a vancomycin-resistant Staphylococcus aureus isolated from Kolkata (South Asia). J Med Microbiol 57:72-79

39. Lessard IA, Walsh CT (1999) Mutational analysis of active-site residues of the enterococcal D-ala-D-Ala dipeptidase VanX and comparison with Escherichia coli D-ala-D-Ala ligase and D-alaD-Ala carboxypeptidase VanY. Chem Biol 6:177-187

40. Courvalin P (2006) Vancomycin resistance in Gram-positive cocci. Clin Infect Dis 42:S25-S34

41. Jensen SO, Lyon BR (2009) Genetics of antimicrobial resistance in Staphylococcus aureus. Future Microbiol 4:565-582

42. Jackson MP, Iandolo JJ (1986) Cloning and expression of the exfoliative toxin B gene from Staphylococcus aureus. J Bacteriol 166:574-580

43. Nishifuji K, Sugai M, Amagai M (2008) Staphylococcal exfoliative toxins: "Molecular scissors" of bacteria that attack the cutaneous defense barrier in mammals. J Dermatol Sci 49:21-31

44. Yamaguchi T, Nishifuji K, Sasaki M, Fudaba Y, Aepfelbacher M, Takata T, Ohara M, Komatsuzawa H, Amagai M, Sugai M (2002) Identification of the Staphylococcus aureus etd pathogenicity island which encodes a novel exfoliative toxin, ETD, and EDIN-B. Infect Immun 70:5835-5845

45. Yamaguchi T, Hayashi T, Takami H, Ohnishi M, Murata T, Nakayama K, Asakawa K, Ohara M, Komatsuzawa H, Sugai M (2001) Complete nucleotide sequence of a Staphylococcus aureus exfoliative toxin B plasmid and identification of a novel ADP-ribosyltransferase, EDIN-C. Infect Immun 69:7760-7771

46. Plano LR (2004) Staphylococcus aureus exfoliative toxins: how they cause disease. J Invest Dermatol 122:1070-1077 
47. Goerke C, Pantucek R, Holtfreter S, Schulte B, Zink M, Grumann D, Broker BM, Doskar J, Wolz C (2009) Diversity of prophages in dominant Staphylococcus aureus clonal lineages. J Bacteriol 191:3462-3468

48. Mann NH (2008) The potential of phages to prevent MRSA infections. Res Microbiol 159:400-405

49. Coleman DC, Sullivan DJ, Russell RJ, Arbuthnott JP, Carey BF, Pomeroy HM (1989) Staphylococcus aureus bacteriophages mediating the simultaneous lysogenic conversion of beta-lysin, staphylokinase and enterotoxin A: molecular mechanism of triple conversion. J Gen Microbiol 135:1679-1697

50. van Wamel W, Rooijakkers S, Ruyken M, van Kessel K, van Strijp J (2006) The innate immune modulators staphylococcal complement inhibitor and chemotaxis inhibitory protein of Staphylococcus aureus are located on beta-hemolysin-converting bacteriophages. J Bacteriol 188:1310-1315

51. Szmigielski S, Prevost G, Monteil H, Colin DA, Jeljaszewicz J (1999) Leukocidal toxins of staphylococci. Zentralbl Bakteriol 289:185-201

52. Fitzgerald JR, Monday SR, Foster TJ, Bohach GA, Hartigan PJ, Meaney WJ, Smyth CJ (2001) Characterization of a putative pathogenicity island from bovine Staphylococcus aureus encoding multiple superantigens. J Bacteriol 183:63-70

53. Novick R, Subedi A (2007) The SaPIs: mobile pathogenicity islands of staphylococcus. Chem Immunol Allergy 93:42-57

54. Novick RP (2003) Mobile genetic elements and bacterial toxinoses: the superantigen-encoding pathogenicity islands of Staphylococcus aureus. Plasmid 49:93-105

55. Ubeda C, Tormo MA, Cucarella C, Trotonda P, Foster TJ, Lasa I, Penades JR (2003) Sip, an integrase protein with excision, circularization and integration activities, defines a new family of mobile Staphylococcus aureus pathogenicity islands. Mol Microbiol 49:193-210

56. Yarwood JM, McCormick JK, Paustian ML, Orwin PM, Kapur V, Schlievert PM (2002) Characterization and expression analysis of Staphylococcus aureus pathogenicity island 3. J Biol Chem 277:13138-13147

57. Carles U, Ma Angeles T, Carme C, Pilar T, Timothy JF, Inigo L, Jose RP (2003) Sip, an integrase protein with excision, circularization and integration activities, defines a new family of mobile Staphylococcus aureus pathogenicity islands. Mol Microbiol 49:93-210

58. Tormo MA, Knecht E, Gotz F, Lasa I, Penades JR (2005) Bapdependent biofilm formation by pathogenic species of Staphylococcus: evidence of horizontal gene transfer? Microbiology 151:2465-2475

59. Tormo MA, Ferrer MD, Maiques E, Ubeda C, Selva L, Lasa I, Calvete JJ, Novick RP, Penades JR (2008) Staphylococcus aureus pathogenicity island DNA is packaged in particles composed of phage proteins. J Bacteriol 190:2434-2440

60. Ubeda C (2005) Antibiotic-induced SOS response promotes horizontal dissemination of pathogenicity island-encoded virulence factors in staphylococci. Mol Microbiol 56:836-844

61. Ito T, Okuma K, Ma XX, Yuzawa H, Hiramatsu K (2003) Insights on antibiotic resistance of Staphylococcus aureus from its whole genome: Genomic island SCC. Drug Resist Update 6:41-52

62. Dobrindt U, Hochhut B, Hentschel U, Hacker J (2004) Genomic islands in pathogenic and environmental microorganisms. Nat Rev Micro 2:414-424

63. Waldron D, Lindsay J (2006) Sau1: a novel lineage-specific type I restriction-modification system that blocks horizontal gene transfer into Staphylococcus aureus and between S. aureus isolates of different lineages. J Bacteriol 188:5578-5585

64. Lina G, Bohach Gregory A, Nair Sean P, Hiramatsu K, JouvinMarche E, Mariuzza R (2004) Standard nomenclature for the superantigens expressed by Staphylococcus. J Infect Dis 189:2334-2336

65. Tsuru T, Kobayashi I (2008) Multiple genome comparison within a bacterial species reveals a unit of evolution spanning two adjacent genes in a tandem paralog cluster. Mol Biol Evol 25:2457-2473

66. Jevons MP, Rolinson GN, Knox R (1961) “Celbenin"-resistant staphylococci. BMJ 1:124-126

67. Severin A, Wu SW, Tabei K, Tomasz A (2005) High-level $\beta$-lactam resistance and cell wall synthesis catalyzed by the mecA homologue of Staphylococcus sciuri introduced into Staphylococcus aureus. J Bacteriol 187:6651-6658

68. Wu S, Piscitelli C, De Lencastre H, Tomasz A (1996) Tracking the evolutionary origin of the methicillin resistance gene: cloning and sequencing of a homologue of mecA from a methicillin susceptible strain of Staphylococcus sciuri. Microb Drug Resist 2:435-441

69. Chongtrakool P, Ito T, Ma XX, Kondo Y, Trakulsomboon S, Tiensasitorn C, Jamklang M, Chavalit T, Song J-H, Hiramatsu K (2006) Staphylococcal cassette chromosome mec (SCCmec) typing of methicillin-resistant Staphylococcus aureus strains isolated in 11 Asian countries: a proposal for a new nomenclature for SCCmec elements. Antimicrob Agents Chemother 50:1001-1012

70. de Lencastre H, Oliveira D, Tomasz A (2007) Antibiotic resistant Staphylococcus aureus: a paradigm of adaptive power. Curr Opin Microbiol 10:428-435

71. International Working Group on the Classification of Staphylococcal Cassette Chromosome Elements (IWG-SCC) (2009) Classification of staphylococcal cassette chromosome mec (SCCmec): guidelines for reporting novel SCCmec elements. Antimicrob Agents Chemother 53:4961-4967

72. Ma XX, Ito T, Tiensasitorn C, Jamklang M, Chongtrakool P, Boyle-Vavra S, Daum RS, Hiramatsu K (2002) Novel type of staphylococcal cassette chromosome mec identified in community-acquired methicillin-resistant Staphylococcus aureus strains. Antimicrob Agents Chemother 46:1147-1152

73. Sitthisak S, Knutsson L, Webb JW, Jayaswal RK (2007) Molecular characterization of the copper transport system in Staphylococcus aureus. Microbiol 153:4274-4283

74. Zhang K, McClure J-A, Elsayed S, Conly JM (2009) Novel staphylococcal cassette chromosome mec type, tentatively designated type VIII, harboring class a mec and type $4 \mathrm{ccr}$ gene complexes in a Canadian epidemic strain of methicillin-resistant Staphylococcus aureus. Antimicrob Agents Chemother 53: 531-540

75. Luong TT, Ouyang S, Bush K, Lee CY (2002) Type 1 capsule genes of Staphylococcus aureus are carried in a staphylococcal cassette chromosome genetic element. J Bacteriol 184: 3623-3629

76. Hanssen AM, Sollid JUE (2006) SCCmec in staphylococci: genes on the move. FEMS Immunol Med Microbiol 46:8-20

77. Ellington MJ, Yearwood L, Ganner M, East C, Kearns AM (2008) Distribution of the ACME-arcA gene among methicillinresistant Staphylococcus aureus from England and Wales. J Antimicrob Chemother 61:73-77

78. Goering RV, McDougal LK, Fosheim GE, Bonnstetter KK, Wolter DJ, Tenover FC (2007) Epidemiologic distribution of the arginine catabolic mobile element among selected methicillinresistant and methicillin-susceptible Staphylococcus aureus isolates. J Clin Microbiol 45:1981-1984

79. Miragaia M, de Lencastre H, Perdreau-Remington F, Chambers HF, Higashi J, Sullam PM, Lin J, Wong KI, King KA, Otto M, Sensabaugh GF, Diep BA (2009) Genetic diversity of arginine catabolic mobile element in Staphylococcus epidermidis. PLoS One 4:e 7722 
80. Diep BA, Stone GG, Basuino L, Graber CJ, Miller A, des Etages S-A, Jones A, Palazzolo-Ballance AM, Perdreau-Remington F, Sensabaugh GF, DeLeo FR, Chambers HF (2008) The arginine catabolic mobile element and staphylococcal chromosomal cassette mec linkage: convergence of virulence and resistance in the USA300 clone of methicillin-resistant Staphylococcus aureus. J Infect Dis 197:1523-1530

81. Montgomery CP, Boyle-Vavra S, Daum RS (2009) The arginine catabolic mobile element is not associated with enhanced virulence in experimental invasive disease caused by the community-associated methicillin-resistant Staphylococcus aureus USA300 genetic background. Infect Immun 77: 2650-2656

82. Byrne ME, Rouch DA, Skurray RA (1989) Nucleotide sequence analysis of IS256 from the Staphylococcus aureus gentamicintobramycin-kanamycin-resistance transposon Tn4001. Gene 81:361-367

83. Fiandt M, Szybalski W, Malamy MH (1972) Polar mutations in lac, gal and phage lambda consist of a few IS-DNA sequences inserted with either orientation. Mol Gen Genet 119:223-231

84. Jansen A, Türck M, Szekat C, Nagel M, Clever I, Bierbaum G (2007) Role of insertion elements and yycfg in the development of decreased susceptibility to vancomycin in Staphylococcus aureus. Int J Med Microbiol 297:205-215

85. Jaurin B, Normark S (1983) Insertion of IS2 creates a novel ampC promoter in Escherichia coli. Cell 32:809-816

86. Rouch DA, Byrne ME, Kong YC, Skurray RA (1987) The aacAaphD gentamicin and kanamycin resistance determinant of Tn4001 from Staphylococcus aureus: expression and nucleotide sequence analysis. J Gen Microbiol 133:3039-3052

87. Rouch DA, Messerotti LJ, Loo LSL, Jackson CA, Skurray RA (1989) Trimethoprim resistance transposon Tn4003 from Staphylococcus aureus encodes genes for a dihydrofolate reductase and thymidylate synthetase flanked by three copies of IS257. Mol Microbiol 3:161-175

88. Phillips S, Novick RP (1979) Tn554—a site-specific repressorcontrolled transposon in Staphylococcus aureus. Nature 278:476-478

89. Soge OO, Beck NK, White TM, No DB, Roberts MC (2008) A novel transposon, Tn6009, composed of a Tn916 element linked with a Staphylococcus aureus mer operon. J Antimicrob Chemother 62:674-680

90. Lange CC, Werckenthin C, Schwarz S (2003) Molecular analysis of the plasmid-borne aacA/aphD resistance gene region of coagulase-negative staphylococci from chickens. J Antimicrob Chemother 51:1397-1401

91. Palumbi SR (2001) Humans as the world's greatest evolutionary force. Science 293:1786-1790

92. Carles U, Elisa M, Erwin K, Inigo L, Richard PN, José RP (2005) Antibiotic-induced SOS response promotes horizontal dissemination of pathogenicity island-encoded virulence factors in staphylococci. Mol Microbiol 56:836-844

93. Maiques E, Ubeda C, Campoy S, Salvador N, Lasa I, Novick RP, Barbe J, Penades JR (2006) $\beta$-Lactam antibiotics induce the SOS response and horizontal transfer of virulence factors in Staphylococcus aureus. J Bacteriol 188:2726-2729

94. Sung JM-L, Lloyd DH, Lindsay JA (2008) Staphylococcus aureus host specificity: comparative genomics of human versus animal isolates by multi-strain microarray. Microbiology 154:1949-1959

95. van Belkum A, Melles DC, Peeters JK, van Leeuwen WB, van Duijkeren E, Huijsdens XW, Spalburg E, de Neeling AJ, Verbrugh HA, Dutch Working Party on Surveillance and Research of MRSA-SOM (2008) Methicillin-resistant and -susceptible Staphylococcus aureus sequence type 398 in pigs and humans. Emerg Infect Dis 14:479-483
96. van Loo I, Huijsdens X, Tiemersma E, de Neeling A, van de Sande-Bruinsma N, Beaujean D, Voss A, Kluytmans J (2007) Emergence of methicillin-resistant Staphylococcus aureus of animal origin in humans. Emerg Infect Dis 13:1834-1839

97. Vitale CB, Gross TL, Weese JS (2006) Methicillin-resistant Staphylococcus aureus in cat and owner. Emerg Infect Dis 12:1998-2000

98. Weese JS, Archambault M, Willey BM, Hearn P, Kreiswirth BN, Said-Salim B, McGeer A, Likhoshvay Y, Prescott JF, Low DE (2005) Methicillin-resistant Staphylococcus aureus in horses and horse personnel, 2000-2002. Emerg Infect Dis 11:430-435

99. Lowder BV, Guinane CM, Ben Zakour NL, Weinert LA, Conway-Morris A, Cartwright RA, Simpson AJ, Rambaut A, Nübel U, Fitzgerald JR (2009) Recent human-to-poultry host jump, adaptation, and pandemic spread of Staphylococcus aureus. Proc Natl Acad Sci USA 106:19545-19550

100. Byrne ME, Gillespie MT, Skurray RA (1991) 4', 4" adenyltransferase activity on conjugative plasmids isolated from Staphylococcus aureus is encoded on an integrated copy of pUB110. Plasmid 25:70-75

101. Kadlec K, Schwarz S (2009) Novel ABC transporter gene, $\operatorname{vga}(\mathrm{C})$, located on a multiresistance plasmid from a porcine methicillin-resistant Staphylococcus aureus ST398 strain. Antimicrob Agents Chemother 53:3589-3591

102. Lelievre H, Lina G, Jones ME, Olive C, Forey F, RousselDelvallez M, Nicolas-Chanoine M-H, Bebear CM, Jarlier V, Andremont A, Vandenesch F, Etienne J (1999) Emergence and spread in French hospitals of methicillin-resistant Staphylococcus aureus with increasing susceptibility to gentamicin and other antibiotics. J Clin Microbiol 37:3452-3457

103. Broer S, Ji G, Broer A, Silver S (1993) Arsenic efflux governed by the arsenic resistance determinant of Staphylococcus aureus plasmid pI258. J Bacteriol 175:3480-3485

104. Ji G, Silver S (1992) Regulation and expression of the arsenic resistance operon from Staphylococcus aureus plasmid pI258. J Bacteriol 174:3684-3694

105. Kaase M, Lenga S, Friedrich S, Szabados F, Sakinc T, Kleine B, Gatermann SG (2008) Comparison of phenotypic methods for penicillinase detection in Staphylococcus aureus. Clin Microbiol Infect 14:614-616

106. Hou Z, Meng J-R, Zhao J-R, Hu B-Q, Liu J, Yan X-J, Jia M, Luo X-X (2007) Inhibition of beta-lactamase-mediated oxacillin resistance in Staphylococcus aureus by a deoxyribozyme. Acta Pharmacol Sin 28:1775-1782

107. Gennimata D, Davies J, Tsiftsoglour S (1996) Bleomycin resistance in Staphylococcus aureus clinical isolates. J Antimicrob Chemother 37:65-75

108. McElgunn CJ, Zahurul M, Bhuyian A, Sugiyama M (2002) Integration analysis of pSK41 in the chromosome of a methicillin-resistant Staphylococcus aureus K-1. J Basic Microbiol 42:190-200

109. Crupper SS, Worrell V, Stewart GC, Iandolo JJ (1999) Cloning and expression of cadD, a new cadmium resistance gene of Staphylococcus aureus. J Bacteriol 181:4071-4075

110. Nies DH (1992) Resistance to cadmium, cobalt, zinc, and nickel in microbes. Plasmid 27:17-28

111. Massidda O, Mingoia M, Fadda D, Whalen MB, Montanari MP, Varaldo PE (2006) Analysis of the beta-lactamase plasmid of borderline methicillin-susceptible Staphylococcus aureus: focus on bla complex genes and cadmium resistance determinants cadD and cadX. Plasmid 55:114-127

112. Projan SJ, Novick R (1988) Comparative analysis of five related staphylococcal plasmids. Plasmid 19:203-221

113. Projan SJ, Moghazeh S, Novick RP (1988) Nucleotide sequence of $\mathrm{pS} 194$, a streptomycin-resistance plasmid from Staphylococcus aureus. Nucl Acids Res 16:2179-2188 
114. Kehrenberg C, Schwarz S (2006) Distribution of florfenicol resistance genes $f e x A$ and $c f r$ among chloramphenicol-resistant staphylococcus isolates. Antimicrob Agents Chemother 50:1156-1163

115. Schwarz S, Kehrenberg C, Doublet B, Cloeckaert A (2004) Molecular basis of bacterial resistance to chloramphenicol and florfenicol. FEMS Microbiol Rev 28:519-542

116. Tennent JM, Young H-K, Lyon BR, Amyes SGB, Skurray RA (1988) Trimethoprim resistance determinants encoding a dihydrofolate reductase in clinical isolates of Staphylococcus aureus and coagulase-negative staphylococci. J Med Microbiol 26:67-73

117. Otsuka T, Zaraket H, Takano T, Saito K, Dohmae S, Higuchi W, Yamamoto T (2007) Macrolide-lincosamide-streptogramin B resistance phenotypes and genotypes among Staphylococcus aureus clinical isolates in Japan. Clin Microbiol Infect 13:325-327

118. Westh H, Hougaard D, Vuust J, Rosdahl V (1995) Prevalence of erm gene classes in erythromycin-resistant Staphylococcus aureus strains isolated between 1959 and 1988. Antimicrob Agents Chemother 39:369-373

119. Jappe U, Heuck D, Strommenger B, Wendt C, Werner G, Altmann D, Witte W (2008) Staphylococcus aureus in dermatology outpatients with special emphasis on community-associated methicillin-resistant strains. J Invest Dermatol 128:2655-2664

120. O'Brien FG, Price C, Grubb WB, Gustafson JE (2002) Genetic characterization of the fusidic acid and cadmium resistance determinants of Staphylococcus aureus plasmid pUB101. J Antimicrob Chemother 50:313-321

121. de Oliveira NEM, Cavalcanti EDAC, Laport MS, Bastos MDCDF, Giambiagi-deMarval M (2009) Constitutive expression of the ileS-2 gene responsible for high-level mupirocin resistance in Staphylococcus aureus. J Med Microbiol 58:1582-1584

122. Patel JB, Gorwitz RJ, Jernigan JA (2009) Antimicrobial resistance: mupirocin resistance. Clin Infect Dis 49:935-941

123. Laddaga RA, Chu L, Misra TK, Silver S (1987) Nucleotide sequence and expression of the mercurial-resistance operon from Staphylococcus aureus plasmid pI258. Proc Natl Acad Sci USA 84:5106-5110

124. Matsuoka M, Endou K, Kobayashi H, Inoue M, Nakajima Y (1998) A plasmid that encodes three genes for resistance to macrolide antibiotics in Staphylococcus aureus. FEMS Microbiol Lett 167:221-227

125. Antonio M, McFerran N, Pallen MJ (2002) Mutations affecting the Rossman fold of isoleucyl-tRNA synthetase are correlated with low-level mupirocin resistance in Staphylococcus aureus. Antimicrob Agents Chemother 46:438-442

126. Littlejohn TG, DiBerardino D, Messerotti LJ, Spiers SJ, Skurray RA (1991) Structure and evolution of a family of genes encoding antiseptic and disinfectant resistance in Staphylococcus aureus. Gene 101:59-66

127. Liu Q, Liu M, Wu Q, Li C, Zhou T, Ni Y (2009) Sensitivities to biocides and distribution of biocide resistance genes in quaternary ammonium compound tolerant Staphylococcus aureus isolated in a teaching hospital. Scan J Infect Dis 41:403-409

128. Nakaminami H, Noguchi N, Nishijima S, Kurokawa I, Sasatsu M (2008) Characterization of the pTZ2162 encoding multidrug efflux gene qacB from Staphylococcus aureus. Plasmid 60:108-117

129. Bismuth R, Zilhao R, Sakamoto H, Guesdon JL, Courvalin P (1990) Gene heterogeneity for tetracycline resistance in Staphylococcus spp. Antimicrob Agents Chemother 34:1611-1614

130. Guay GG, Khan SA, Rothstein DM (1993) The tet(K) gene of plasmid pT181 of Staphylococcus aureus encodes an efflux protein that contains 14 transmembrane helices. Plasmid $30: 163-166$
131. Trzcinski K, Cooper BS, Hryniewicz W, Dowson CG (2000) Expression of resistance to tetracyclines in strains of methicillinresistant Staphylococcus aureus. J Antimicrob Chemother 45:763-770

132. Korczynska M, Mukhtar TA, Wright GD, Berghuis AM (2007) Structural basis for streptogramin B resistance in Staphylococcus aureus by virginiamycin B lyase. Proc Natl Acad Sci 104:10388-10393

133. Mukhtar TA, Koteva KP, Hughes DW, Wright GD (2001) Vgb from Staphylococcus aureus inactivates streptogramin B antibiotics by an elimination mechanism not hydrolysis $\dagger$. Biochem 40:8877-8886

134. Rowland S-J, Dyke KGH (1990) Tn552, a novel transposable element from Staphylococcus aureus. Mol Microbiol 4:961-975

135. Dubin DT, Chikramane SG, Inglis B, Matthews PR, Stewart PR (1992) Physical mapping of the mec region of an Australian methicillin-resistant Staphylococcus aureus lineage and a closely related American strain. J Gen Microbiol 138:169-180

136. Babich K, Engle M, Skinner JS, Laddaga RA (1991) Deletion mutant analysis of the Staphylococcus aureus plasmid pI258 mercury-resistance determinant. Can J Microbiol 37:624-631

137. Bogdanova E, Minakhin L, Bass I, Volodin A, Hobman JL, Nikiforov V (2001) Class II broad-spectrum mercury resistance transposons in Gram-positive bacteria from natural environments. Res Microbiol 152:503-514

138. Postma B, Poppelier MJ, van Galen JC, Prossnitz ER, van Strijp JAG, de Haas CJC, van Kessel KPM (2004) Chemotaxis inhibitory protein of Staphylococcus aureus binds specifically to the c5a and formylated peptide receptor. J Immunol 172: 6994-7001

139. Altboum Z, Hertman I, Sarid S (1985) Penicillinase plasmidlinked genetic determinants for enterotoxins $\mathrm{b}$ and $\mathrm{c} 1$ production in Staphylococcus aureus. Infect Immun 47:514-521

140. Frea JI, McCoy E, Strong FM (1963) Purification of type b staphylococcal enterotoxin. J Bacteriol 86:1308-1313

141. Avena RM, Bergdoll MS (1967) Purification and some physicochemical properties of enterotoxin C, Staphylococcus aureus strain 361. Biochem 6:1474-1480

142. Bayles KW, Iandolo JJ (1989) Genetic and molecular analyses of the gene encoding staphylococcal enterotoxin D. J Bacteriol 171:4799-4806

143. Zhang S, Iandolo JJ, Stewart GC (1998) The enterotoxin D plasmid of Staphylococcus aureus encodes a second enterotoxin determinant (sej). FEMS Microbiol Lett 168:227-233

144. Chiang Y-C, Chang L-T, Lin C-W, Yang C-Y, Tsen H-Y (2006) PCR primers for the detection of staphylococcal enterotoxins $\mathrm{K}$, $\mathrm{L}$, and $\mathrm{M}$ and survey of staphylococcal enterotoxin types in Staphylococcus aureus isolates from food poisoning cases in Taiwan. J Food Protect 69:1072-1079

145. Sumby P, Waldor MK (2003) Transcription of the toxin genes present within the staphylococcal phage phiSa $3 \mathrm{~ms}$ is intimately linked with the phage's life cycle. J Bacteriol 185:6841-6851

146. Chiang Y-C, Liao W-W, Fan C-M, Pai W-Y, Chiou C-S, Tsen H-Y (2008) PCR detection of staphylococcal enterotoxins (SEs) $\mathrm{N}, \mathrm{O}, \mathrm{P}, \mathrm{Q}, \mathrm{R}, \mathrm{U}$, and survey of SE types in Staphylococcus aureus isolates from food-poisoning cases in Taiwan. Int $\mathrm{J}$ Food Microbiol 121:66-73

147. Brussow H, Canchaya C, Hardt W-D (2004) Phages and the evolution of bacterial pathogens: from genomic rearrangements to lysogenic conversion. Microbiol Mol Biol Rev 68:560-602

148. Cabrera G, Xiong A, Uebel M, Singh VK, Jayaswal RK (2001) Molecular characterization of the iron-hydroxamate uptake system in Staphylococcus aureus. Appl Environ Microbiol 67:1001-1003

149. Essmann F, Bantel H, Totzke G, Engels IH, Sinha B, SchulzeOsthoff K, Janicke RU (2003) Staphylococcus aureus alpha- 
toxin-induced cell death: predominant necrosis despite apoptotic caspase activation. Cell Death Differ 10:1260-1272

150. Highlander S, Hulten K, Qin X, Jiang H, Yerrapragada S, Mason E, Shang Y, Williams T, Fortunov R, Liu Y, Igboeli O, Petrosino J, Tirumalai M, Uzman A, Fox G, Cardenas A, Muzny D, Hemphill L, Ding Y, Dugan S, Blyth P, Buhay C, Dinh H, Hawes A, Holder M, Kovar C, Lee S, Liu W, Nazareth L, Wang Q, Zhou J, Kaplan S, Weinstock G (2007) Subtle genetic changes enhance virulence of methicillin resistant and sensitive Staphylococcus aureus. BMC Microbiol 7:99

151. Makris G, Wright JD, Ingham E, Holland KT (2004) The hyaluronate lyase of Staphylococcus aureus-a virulence factor? Microbiol 150:2005-2013

152. Zou D, Kaneko J, Narita S, Kamio Y (2000) Prophage, phiPV83-pro, carrying panton-valentine leukocidin genes, on the Staphylococcus aureus P83 chromosome: comparative analysis of the genome structures of phiPV83-pro, phiPVL, phi11, and other phages. Biosci Biotech Biochem 64:2631-2643

153. Barrio MB, Rainard P, Prévost G (2006) LukM/LukF'-PV is the most active Staphylococcus aureus leukotoxin on bovine neutrophils. Microb Infect 8:2068-2074

154. Gillet Y, Issartel B, Vanhems P, Fournet JC, Lina G, Bes M, Vandenesch F, Piémont Y, Brousse N, Floret D, Etienne J (2002) Association between Staphylococcus aureus strains carrying gene for Panton-Valentine leukocidin and highly lethal necrotising pneumonia in young immunocompetent patients. Lancet 359:753-759

155. Lina G, Piémont $\mathrm{Y}$, Godail-Gamot F, Bes M, Peter MO, Gauduchon V, Vandenesch F, Etienne J (1999) Involvement of Panton-Valentine leukocidin-producing Staphylococcus aureus in primary skin infections and pneumonia. Clin Infect Dis 29:1128-1132

156. Panton PN, Valentine FCO (1932) Staphylococcal toxin. Lancet 219:506-508

157. Tristan A, Bes M, Meugnier H, Lina G, Bozdogan B, Courvalin P, Reverdy ME, Enright MC, Vandenesch F, Etienne J (2007) Global distribution of Panton-Valentine leukocidin-positive methicillin-resistant Staphylococcus aureus, 2006. Emerg Infect Dis 13:594-600

158. Voyich JM, Otto M, Mathema B, Braughton KR, Whitney AR, Welty D, Long RD, Dorward DW, Gardner DJ, Lina G, Kreiswirth BN, DeLeo FR (2006) Is Panton-Valentine leukocidin the major virulence determinant in community-associated methicillin-resistant Staphylococcus aureus disease? J Infect Dis 194:1761-1770

159. Queck SY, Khan BA, Wang R, Bach T-HL, Kretschmer D, Chen L, Kreiswirth BN, Peschel A, DeLeo FR, Otto M (2009) Mobile genetic element-encoded cytolysin connects virulence to methicillin resistance in MRSA. PLoS Pathog 5:e1000533
160. Mehlin C, Headley CM, Klebanoff SJ (1999) An inflammatory polypeptide complex from Staphylococcus epidermidis: isolation and characterization. J Exp Med 189:907-918

161. Vuong C, Dürr M, Carmody AB, Peschel A, Klebanoff SJ, Otto M (2004) Regulated expression of pathogen-associated molecular pattern molecules in Staphylococcus epidermidis: quorumsensing determines pro-inflammatory capacity and production of phenol-soluble modulins. Cell Microbiol 6:753-759

162. Werbick C, Becker K, Mellmann A, Juuti KM, von Eiff C, Peters G, Kuusela PI, Friedrich AW, Sinha B (2007) Staphylococcal chromosomal cassette mec type I, spa type, and expression of pls are determinants of reduced cellular invasiveness of methicillin-resistant Staphylococcus aureus isolates. J Infect Dis 195:1678-1685

163. Stec-Niemczyk J, Pustelny K, Kisielewska M, Bista M, Boulware KT, Stennicke HR, Thogersen IB, Daugherty PS, Enghild JJ, Baczynski K, Popowicz GM, Dubin A, Potempa J, Dubin G (2009) Structural and functional characterization of splA, an exclusively specific protease of Staphylococcus aureus. J Biochem 419:555-564

164. Takeuchi S, Matsunaga K, Inubushi S, Higuchi H, Imaizumi K, Kaidoh T (2002) Structural gene and strain specificity of a novel cysteine protease produced by Staphylococcus aureus isolated from a diseased chicken. Vet Microbiol 89:201-210

165. Rooijakkers SHM, Ruyken M, Roos A, Daha MR, Presanis JS, Sim RB, van Wamel WJB, van Kessel KPM, van Strijp JAG (2005) Immune evasion by a staphylococcal complement inhibitor that acts on C3 convertases. Nat Immunol 6:920-927

166. Fraser JD, Proft $T$ (2008) The bacterial superantigen and superantigen-like proteins. Immunol Rev 225:226-243

167. Bokarewa M, Tarkowski A (2004) Human alpha-defensins neutralize fibrinolytic activity exerted by staphylokinase. Thromb Haemost 91:991-999

168. Jin T, Bokarewa M, Foster T, Mitchell J, Higgins J, Tarkowski A (2004) Staphylococcus aureus resists human defensins by production of staphylokinase, a novel bacterial evasion mechanism. J Immunol 172:1169-1176

169. Rooijakkers SHM, van Wamel WJB, Ruyken M, van Kessel KPM, van Strijp JAG (2005) Anti-opsonic properties of staphylokinase. Microb Infect 7:476-484

170. Kreiswirth BN, Projan SJ, Schlievert PM, Novick RP (1989) Toxic shock syndrome toxin-1 is encoded by a variable genetic element. Rev Infect Dis 11:S75-S82

171. Lindsay JA, Ruzin A, Ross HF, Kurepina N, Novick RP (1998) The gene for toxic shock toxin is carried by a family of mobile pathogenicity islands in Staphylococcus aureus. Mol Microbiol 29:527-543 